\begin{tabular}{|c|c|c|}
\hline $\operatorname{INF}_{P \cup B L I C A T I O N}$ & $\begin{array}{l}\text { International Journal of Advanced Engineering, Management and Science } \\
\text { (IJAEMS) } \\
\text { ISSN: 2454-1311 } \\
\text { Vol-7, Issue-3; Mar, } 2021 \\
\text { Journal Home Page Available: https://ijaems.com/ } \\
\text { Journal DOI: } \underline{\text { https://dx.doi.org/10.22161/ijaems }} \\
\text { Article DOI: } \text { https://dx.doi.org/10.22161/ijaems.73.12 }\end{array}$ & (1) \\
\hline
\end{tabular}

\title{
Different Language Usage on Social Media
}

\author{
Maria Angela S. Esteron
}

English Teacher, College of Education, Central Luzon State University, Philippines

Received: 14 Dec 2020; Received in revised form: 03 Feb 2021; Accepted: 21 Feb 2021; Available online: 28 Mar 2021

C2021 The Author(s). Published by Infogain Publication. This is an open access article under the CC BY license

(https://creativecommons.org/licenses/by/4.0/).

\begin{abstract}
The research presented the effects of Social Media on the formation of new words that are being used by the Social Media users that often includes in the formal use of language in the academe. The emergence of different Social Networking Sites (SNSS) such as Facebook, Twitter, and E-mail have driven a more advanced change in the way people communicate. The study aimed to assess how Social Media affects the formal English Language used in the academe. The result of the study also highlighted how often do Social Media users of the Central Luzon State University, College of Education use the proper abbreviations, exclamatory spelling of emoticons, use letter homophones, acronyms, commit misspelled words, use shortening of words, use numbers to represents words, and use combination of two different language in their papers. The qualitative method of research used the survey technique and was utilized for gathering data. The questionnaires serve as the instrument for collecting data. 50 students of the College of Education, English Majors of the said university are the respondents.
\end{abstract}

Keywords — academe, language, new words, social media, usage.

\section{INTRODUCTION}

\section{A. BACKGROUND OF THE STUDY}

English Language is said to be the universal language and learning it, means having access to the world, to other people, ideas, ways of thinking and literature. It is the medium for teaching different subjects in the academe and also a medium of knowledge in transferring and sharing certain ideas and feelings. English is one of the important way of communication used among people in different field such as in business, advertisements, engineering mechanics and so on and so forth. That is why English language proficiency is now a must in all aspects of everyday life for us to be able to engage in the globalization.

Nowadays, people make use of the Social Media that became the major form of communication wherein language use has stuck in various areas especially in the teaching and learning. The emergence of different Social Networking Sites (SNSs) such as Facebook, Twitter, email have driven a more refined revolution in the way people communicate.
According to Simpson (2014), former chief editor of the Oxford English Dictionary said that the words that surround us every day influence the words we use. Since so much of the written language we see is now on the screens of our computers, tablets, and smartphones, language now evolves partly through our interaction with technology. And because the language we use to communicate with each other tends to be more malleable than formal writing, the combination of informal, personal communication and the mass audience afforded by social media is a recipe for rapid change.

The $21^{\text {st }}$ century people has come wherein technologies are emerging so fast, and it is affecting the language tremendously. The number of SNSs users especially among students and teenagers have increased extremely over the years and created Internet slangs, new word and symbols or old words having a new meaning such as in Facebook; from unfriend to "selfie", using Emoticons, acronyms like "ATM" which means at the moment, social media is clearly having an impact on language. In the long run people may tend to bind with 
those words which can strengthen or weaken the student's English Language proficiency.

\section{B. STATEMENT OF THE PROBLEM}

This research aims to answer the central question "How Social Media Affects the Formal English Language used in the Academe?"

- What are the different Language Usage commonly used to communicate through the Social Networking Sites?

- How do people in $21^{\text {st }}$ century aware of the evolution of language and formation of new words brought by the modern technology?

- How does frequent use of internet slang weaken or develop the English language?

- How often do Social Media Users use the proper abbreviations, exclamatory spelling of emoticons, use letter homophones, acronyms, commit misspelled words, use shortening of words, use numbers to represents words, and use combination of two different language?

- How the language of social media affects the formal language used in the academe?

\section{OBJECTIVES OF THE STUDY}

This study entitled "The Different Language Usage in Social Media" aims to meet the following objectives:

1. To determine the socio-demographic characteristics of the respondents from the Fourth year- English Majors of the College of Education, Central Luzon State University including the age, and gender while residing at the aforementioned school.

2. To determine the words that are usually used by the SNS's users.

3. To gain insights from the SNSs users on how often they commit misspelled words or use more than one language combined in conversations.

4. To distinguish how language used in Social media affects the formal language use in the academe.

\section{SIGNIFICANCE OF THE STUDY}

The Researcher

The importance of this study to the researchers is to determine the different language usage in Social Networking Sites and how they use this informal language that will affect the student's attitude to grammar and how they use the internet language in everyday life. This study has a huge impact to the researchers as a translator in the future to be aware on the new generated language used in Social Networking Sites when they will encounter variety of language that has need for translation.
The Students

This study aims to help the students to become aware that misspelling, incorrect use of words and other form of figurative language is not accepted when it comes to formalities and the proper usage of English language. However, students who are engaged in SNSs communication, leading to the creation of new phrases and words seems to be extremely worsening students' vocabulary.

To the Academe

This study is very essential in the academe because it gives awareness to teachers and students regarding on their English Language proficiency. The research may use by the academe in the awareness that language now evolves partly through our interaction with technology. Because the language we use to communicate with each other is the combination of informal, personal communication and the mass audience. In the long run people may tend to bind with those words which can lessen the English Language proficiency.

The Society

The communication styles thus become more informal and more open, and this connects into other aspects of life and culture as we reflect in society. This study in pertains to society that different Language usage in Social Networking Sites has an impact to those people who use in making messages, posting different stories that were placed due to the modernization of technology. Thus, in a society the people will adapt with their writing and speaking strategies as they apply in reality.

The Nation

The significance of this study in the nation will apprehend the evolution of language and the formation of different words that will create another standard or new writing and communication skills due to common use of abbreviations and unusual jargon, thereby damaging students' ability to employ formal literacy skills. English language proficiency is a need to become globally competent that will affect the growth of the economy of the nation.

\section{E. SCOPE AND DELIMITATION}

This study entitled "The Different Language Usage on Social Media" will focus only on the language being created by the social media users and how it affects the English Language. The data gathering will only limit to the students of Central Luzon State University specifically in College of Education and will meet 50 randomly selected students who are avid user of Social Networking Sites such as Facebook, Twitter and etc. 


\section{REVIEW OF RELATED LITERATURE}

According to Thomson Wadsworth (2007) in the Article entitled Social Media Violated English Language he stated that, a language consists of symbols that convey meaning, also has rules for combining those symbols that can be used to create messages.

It means that language is a way of expressing ideas and emotions through symbols, it can be in the form of verbal or non- verbal consisting of the use of words in a structure and conventional way. Perhaps, language is dynamic, it can evolve or it can regress therefore language cannot confine in a box because it will be stagnant and will tend to die. Technology nowadays become one of the reasons of the evolution of language.

Language is influenced by many factors such as class, society, and developments in science and technology. But the major influence on English language is and has been the media. Language is influenced by many factors such as class, society, developments in science and technology etc. However the major influence on English language is and has been the media stated by Dr. Neha Sharma (2012) in her study entitled Impact of Social Media on English Language: A Review.

The development and changes of language can be the effect of some groups in the society that people encountered in everyday life. This days the group of LGBT (Lesbian, Gay, Bisexual, and Transgender) community especially the gay group has extreme influence in the language, their "gay language" were adapted by many people and become part of the vocabulary. Another factor is the modernization, the bloom of different gadgets and machineries can influence the language such as the use of the Social Media as a way of communication.

As defined by Andreas Kaplan and Micheal Haenlein(2010), in the book entitled Users of the World, Unite! The Challenges and Opportunities of Social media said that Social Media allows the creation and exchange of user- generated content because it is a group of internetbased applications that build on the ideological and technological foundations of Web 2.0.

Social Media has become one of the most powerful sources for information and news updates through platforms such as Facebook, Blogger, Twitter, Word Press, LinkedIn, Google+ Tumblr, MySpace and Instagram. On the other hand, from a linguistic point of view, the impact of social media reflects on the new words or expression like newsfeeds, viral, hashtag which do not make sense few years ago but meant something completely different than they do nowadays.
Perhaps, Schonfeld (2010) in an article entitled Discourse of Twitter and Social Media, pointed out that Social Networking Sites (SNS) are the most commonly used form of Social Media wherein millions of people around the world can create and produce also millions of different messages.

According to Aydin (2012) in a review of research on Facebook as an educational environment. Education Tech Research Development, the amount of SNS users has increased tremendously over the past five years, especially among teenagers and students. Many users have created Internet slang to communicate and express their thoughts on SNSs and mobile networks.

As the time pass by, technology became part of everyone's life. It is really emerging so fast and the new generation have been immediately adapt this change in our lifestyle. Most of the users are the students for their researches and there studies, and for teenagers who always communicate with their friends through the Social Medias.

In the study entitled Code-switching in E-distance learning education, Abdul Kadir \& Zubir (2012 found that code-switching occurs intentionally and not through lack of competence in the base language. The students used code-switching functions for various purposes such as to capture attention, to show respect, to show empathy and to indicate a shift in topic.

Code switching is concurrent use of more than one language in a sentence. It occurs intentionally because in communicating, you have to relay the message properly and can only make it if you are able to express the thoughts. There are concepts that are present in one language that is not present on the other so through code switching you may able to make them understand the message you are sending.

An earlier study entitled Communicative Functions and Reasons for Code Switching: A Malaysian perspective, Muthusamy (2009) showed that undergraduates of a Malaysian public university had emphasised that lack of register proficiency was also another contributing factor for code switching. The study concluded that the ability of the speakers who were able to speak more than one language fluently played an important role during their interaction.

The interaction is effective if the sender relay the message to the receiver accurately. Using of one or more language in a sentence played an important role during interaction to express the thoughts and ideas that can't be expressed or does not have any translation in the concept of just one language. 
According to Drouin (2011) in the journal entitled College Students' Text Messaging: Journal of Computer Assisted Learning, use of "texts" and literacy skills, he examined the frequency of text messaging, use of "texts" and literacy skills such as reading accuracy, spelling and reading fluency in a sample of college students in America. Co-relational analyses revealed significant positive relationships between text messaging frequency and literacy skills in spelling and reading fluency but significant, negative relationships between texts usage in certain contexts like emails to professors and literacy especially in reading accuracy. Those reportedly using more texts on SNSs and those using more texts in emails to professors had significantly lower reading accuracy scores.

This only means that in some cases texting trough Social Networking Sites can affect the literacy of the students. It may lower reading accuracy because there are internet slangs that may interrupt the vocabulary of the students and can lead to confusion.

In addition to that, Craig (2003) and David (2008) in the study entitled Reflections of Student's Language Usage in Social Networking Sites: Making or Marring Academic English. They said that the longer time that students are engage in texting through the Social Networking Sites the more they improve the student's literacy.

In some instance Social media has a positive effect on the student's learning because it has the potential for use in educational applications. Moreover, social media, enable students to share information, to learn about their classmates, to communicate with their classmates and professors, and to post and discuss relevant class information.

According to Thurairaj et al., (2012) in an article entitled Teachers' Emotions in ELT Material Design. International Journal of Social Science and Humanity, he indicated that the students do improve their language as well as their writing skills, because Facebook and Twitter provides activities preferred by the students and leads to positive language learning.

In using Social Networking Sites such as Facebook, the users may encounter different Linguistic items which they can read and use in posting thus enriches the individual's vocabulary but having different meaning from the standard meaning which is acceptable.

Drouin (2011) in a Journal entitled College students' text messaging, use of textese and literacy skills a Journal of Computer Assisted Learning specified that one should be guide and equipped with a variety of strategies and knowledge of different communication modes, which includes social networking and media platforms like Facebook.

In using the social media some people are not aware of some words that are being formed. The users are not able to differentiate formal language from informal language as more often than not, the students at tertiary level, are inclined to use improper formats and sentences that deaden Standard English.

Cummings (2011) in a study entitled An Experience with Language, ProQuest Dissertations \& Theses: Literature \& Language states that computerassisted language learning will never be able to substitute for teachers because there could be issues of control in administrating relevant exercises in language teaching and learning.

There are some instances that words on Social Media have different meaning with regards to the Philippine Standard English language that was taught in the academe. And in that case teachers are responsible in clearing the meaning.

According to Plester et al., (2008) in a journal entitled Txt msg $\mathrm{n}$ school literacy: Does texting and knowledge of text abbreviations adversely affect children's literacy attainment? Literacy, stated that Internet slang and short message services have been shown to have an impact on the English language. It was estimated that $90 \%$ of school children owned a mobile phone, and $96 \%$ used text messaging. This shows that young people are active "texters". Internet slang was invented for the purpose of saving keystrokes. As typing is much slower than speaking, in order to counter this problem, people started shortening words and creating new words.

Social media users mostly teenagers are avid of chatting with their friends. In order for them to have a long and fast changing of messages they do shortening of words for example the word Please becomes pls. and it makes easier and faster to type.

According to Mphahlele \& Mashamaite (2005), text messaging is deemed to be detrimental to students' language proficiency since students mix this "text language" with the standard language they learn at school. Consequently, students displayed numerous errors ranging from incorrect spellings to "ungrammatical" sentence constructions.

The words and symbols that people use in making messages were placed and adapt with their writing and speaking. The short term of words and some other text languages have been used and combined with the Standard English that is accepted and known by most of the people. They become unaware with the words they are using and 
become a factor to decline the English language proficiency.

According to Craig (2003), in an article entitled Instant messaging: The language of youth literacy, The Boothe Prize Essays 2003, it is also found that texting also threatens students' literacy because it creates undesirable reading and writing habits due to common use of abbreviations and unusual jargon, thereby damaging students' ability to employ formal literacy skills.

Texting may affect the individual's reading and writing skills because of using language of the internet like exclamatory spelling of emoticon such as hahah, acronyms such as LOL and letter homophones such as U. Another thing is that if an individual is interacting with other people the language used might mix with the language of the other.

According to John Simpson (2014), Facebook has also done more than most platforms to offer up new meanings for common words such as friend, like, status, wall, page, and profile. Other new meanings which crop up on social media channels also reflect the dark side of social media: a troll is no longer just a character from Norse folklore, but someone who makes offensive or provocative comments online; a sock puppet is no longer solely a puppet made from an old sock, but a self-serving fake online persona; and astroturfing is no longer simply laying a plastic lawn but also a fake online grass-roots movement.

Furthermore, Scott (2010) in an article entitled Discourse of Twitter and Social Media, believed Emoticons are can pose a significant problem. Depending on the configuration of the concordance software used, some of the characters used in emoticons are not considered valid letters for that system, they may also be interpreted as marking word breaks. In addition some characters may have other special meanings to the system.

Through the use of social media channels like Facebook, Twitter etc. the old words are having a new meaning based on the usage of the words on the said channels. The language of the internet now becomes the language of the world wherein there's no grammar being followed.

According to Mphalele and Mashamaite (2005), in the book entitled The impact of short message service (sms) language on language proficiency of learners and the sms dictionaries: A challenge for educators and lexicographers stated that in order to save space, time, and money. Mobile phone users can communicate with others by using symbols or abbreviated forms of words and sentences.
These Social Networking Sites users utilize every second engaging in Social Networking Sites communication, leading to the creation of new phrases and words. The shortcut language used and created on instant messaging, on the offset, seems to be extremely worsening students' vocabulary.

Language usage is changing because of using different linguistic features in the social media such as Exclamatory Spelling of Emoticons, Letter Homophones, Acronyms, Misspelled Words, Shortening of Words, Numbers representing words, Combination of two different language.

\section{INDENTATIONS AND EQUATIONS}

\section{METHODOLOGY}

This chapter includes the methods and procedures made on gathering the data, research design of the study, the participants, data analysis, and instrument used in the paper.

\section{A. DATA GATHERING PROCEDURES}

The researchers will use a convenience sampling technique in conducting this research by distributing a survey questionnaire to the English Majors in the College of Education at Central Luzon State University to collect data necessary for the study.

\section{B. RESEARCH DESIGN}

This paper used qualitative- interview design because it aims to assess the experiences of the students from the College of Education on how they are affected by the Social Media in the formation of new words that they may use in the formal use of the language in the school.

\section{DATA ANALYSIS}

In analyzing the data, the researcher will get the percentage of the result of the given questionnaire and percentages were primary tools used in analysing and interpreting the data.

\section{RESULTS AND DISCUSSION}

Table 1: Respondent's Socio-Demographic Characteristics

\begin{tabular}{|l|l|l|}
\hline $\begin{array}{c}\text { Respondents } \\
\text { No. }\end{array}$ & Age & Gender \\
\hline $\mathbf{1}$ & 18 & Female \\
\hline $\mathbf{2}$ & 18 & Female \\
\hline $\mathbf{3}$ & 18 & Female \\
\hline $\mathbf{4}$ & 18 & Male \\
\hline
\end{tabular}




\begin{tabular}{|c|c|c|}
\hline 5 & 18 & Male \\
\hline 6 & 18 & Male \\
\hline 7 & 18 & Female \\
\hline 8 & 18 & Male \\
\hline 9 & 18 & Female \\
\hline 10 & 18 & Female \\
\hline 11 & 18 & Male \\
\hline 12 & 18 & Female \\
\hline 13 & 18 & Male \\
\hline 14 & 18 & Female \\
\hline 15 & 19 & Male \\
\hline 16 & 19 & Female \\
\hline 17 & 19 & Female \\
\hline 18 & 19 & Male \\
\hline 19 & 19 & Male \\
\hline 20 & 19 & Male \\
\hline 21 & 19 & Female \\
\hline 22 & 19 & Female \\
\hline 23 & 19 & Male \\
\hline 24 & 19 & Male \\
\hline 25 & 19 & Female \\
\hline 26 & 19 & Female \\
\hline 27 & 19 & Female \\
\hline 28 & 19 & Male \\
\hline 29 & 19 & Female \\
\hline 30 & 19 & Male \\
\hline 31 & 19 & Female \\
\hline 32 & 19 & Male \\
\hline 33 & 19 & Female \\
\hline 34 & 19 & Female \\
\hline 35 & 19 & Female \\
\hline 36 & 20 & Male \\
\hline 37 & 20 & Male \\
\hline 38 & 20 & Female \\
\hline 39 & 20 & Female \\
\hline 40 & 20 & Female \\
\hline 41 & 20 & Female \\
\hline 42 & 20 & Male \\
\hline 43 & 20 & Female \\
\hline 44 & 21 & Female \\
\hline 45 & 21 & Male \\
\hline 46 & 21 & Female \\
\hline 47 & 21 & Male \\
\hline
\end{tabular}

\begin{tabular}{|l|l|l|}
\hline $\mathbf{4 8}$ & 21 & Male \\
\hline $\mathbf{4 9}$ & 22 & Female \\
\hline $\mathbf{5 0}$ & 22 & Female \\
\hline
\end{tabular}

Illustrate the socio-demographic characteristics of the respondents.

The table above shows the demographic characteristics of the respondents wherein the age bracket is from 18-21 years old. 14 out of 50 are 18 years old, 21 of them are 19 years old, eight of the respondents are 20 years old while 5 respondents are 20 years old and the remaining two respondents are 21 years old. With regards to their gender almost all of them are female which has the sum of 29 whereas 21 of them are male.

As supported by (Aydin, 2012) said that the amount of SNS users has increased tremendously over the past five years, especially among teenagers and students.

Table. 2: Represent the answers to the given questions stated in the survey questionnaire

\begin{tabular}{|c|c|c|}
\hline QUESTIONS & NEVER & ONCE \\
\hline 1 & 0 & 0 \\
\hline 2 & 7 & 10 \\
\hline 3 & 6 & 6 \\
\hline 4 & 5 & 8 \\
\hline 5 & 13 & 6 \\
\hline 6 & 4 & 6 \\
\hline 7 & 9 & 12 \\
\hline 8 & 15 & 18 \\
\hline 9 & 12 & 18 \\
\hline 10 & 5 & 4 \\
\hline QUESTIONS & NEVER & ONCE \\
\hline 1 & 0 & 0 \\
\hline 2 & 7 & 10 \\
\hline 3 & 6 & 6 \\
\hline 4 & 5 & 8 \\
\hline 5 & 13 & 6 \\
\hline 6 & 4 & 6 \\
\hline 7 & 9 & 12 \\
\hline 8 & 15 & 18 \\
\hline 9 & 12 & 18 \\
\hline 10 & 5 & 4 \\
\hline QUESTIONS & NEVER & ONCE \\
\hline 1 & 0 & 0 \\
\hline 2 & 7 & 10 \\
\hline 3 & 6 & 6 \\
\hline
\end{tabular}




\begin{tabular}{|c|c|c|}
\hline 4 & 5 & 8 \\
\hline 5 & 13 & 6 \\
\hline 6 & 4 & 6 \\
\hline 7 & 9 & 12 \\
\hline 8 & 15 & 18 \\
\hline 9 & 12 & 18 \\
\hline 10 & 5 & 4 \\
\hline QUESTIONS & NEVER & ONCE \\
\hline 1 & 0 & 0 \\
\hline 2 & 7 & 10 \\
\hline 3 & 6 & 6 \\
\hline 4 & 5 & 8 \\
\hline 5 & 13 & 6 \\
\hline 6 & 4 & 6 \\
\hline 7 & 9 & 12 \\
\hline 8 & 15 & 18 \\
\hline 9 & 12 & 18 \\
\hline 10 & 5 & 4 \\
\hline QUESTIONS & NEVER & ONCE \\
\hline 1 & 0 & 0 \\
\hline 2 & 7 & 10 \\
\hline 3 & 6 & 6 \\
\hline 4 & 5 & 8 \\
\hline 5 & 13 & 6 \\
\hline 6 & 4 & 6 \\
\hline
\end{tabular}

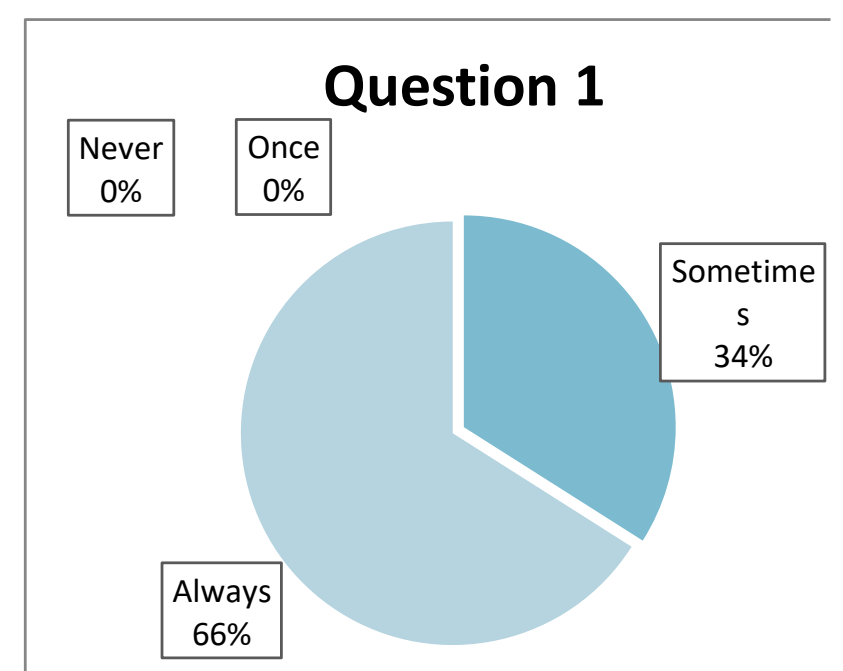

Fig.1: How often you use Social Networking Sites?

In question number one, $66 \%$ of the respondents always use SNSs while the remaining $34 \%$ sometimes use SNSs. None of the respondents had never or even once been logged in to SNSs. Due to the trends of today's generation teenagers are fond of using the different social media platforms, thus everyone already have their own mobile phones and have their own social; media accounts.

Schonfeld (2010) in an article entitled Discourse of Twitter and Social Media, pointed out that Social Networking Sites (SNS) are the most commonly used form of Social Media wherein millions of people around the world can create and produce also millions of different messages.

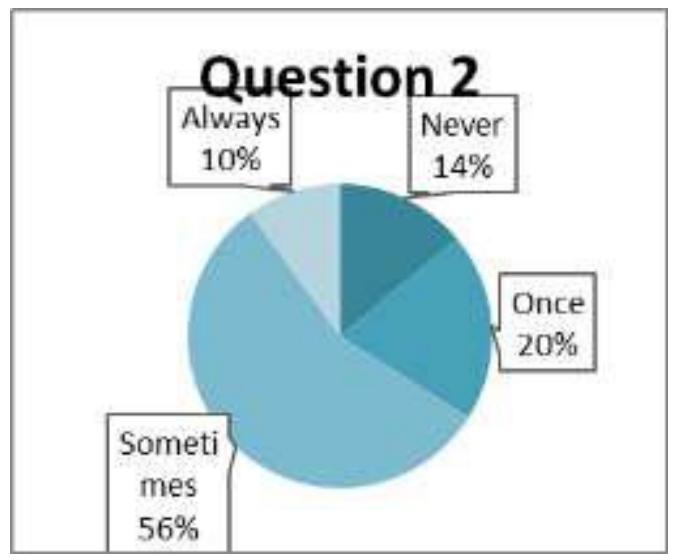

Fig.2: Do you use only one language in communicating with your friends via SNSs and mobile phone in each conversation?

In question number $2.62 \%$ of the respondents sometimes used one language in communicating with their friends via SNSs, while 5\% of them used once, $9 \%$ belongs to always and the remaining $24 \%$ never used only one language in communicating via SNSs.

An earlier study (Muthusamy, 2009) showed that undergraduates of a Malaysian public university had emphasised habitual expression that was related to psychological aspect of behaviour as their main reason for code switching. Lack of register competence was also another contributing factor for code switching. The study concluded that the ability of the interlocutors who were able to speak more than one language fluently played an important role during their interaction. 


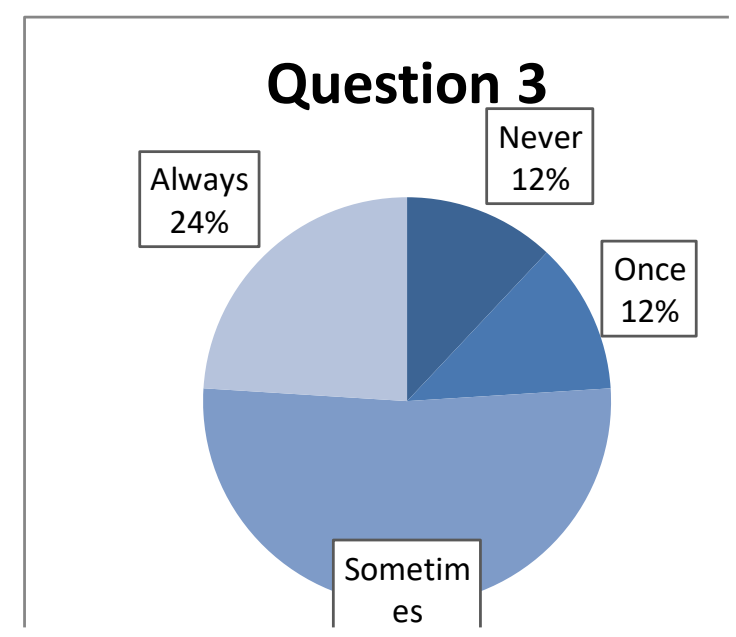

Fig.3:.How often you use proper abbreviations or short forms when communicating with your friends through SNSs?

In question number 3, 6\% of the respondents always used abbreviations or short forms when communicating with friends through SNSs, once and never used abbreviations are with the same percent which is $5 \%$ and the remaining $84 \%$ are the respondents sometimes uses proper abbreviation and short forms of language.

According to Craig (2003), in an article entitled "Instant Messaging: The language of youth literacy, The Boothe Prize Essays 2003," it is also found that texting also threatens students' literacy because it creates undesirable reading and writing habits due to common use of abbreviations and unusual jargon, thereby damaging students' ability to employ formal literacy skills.

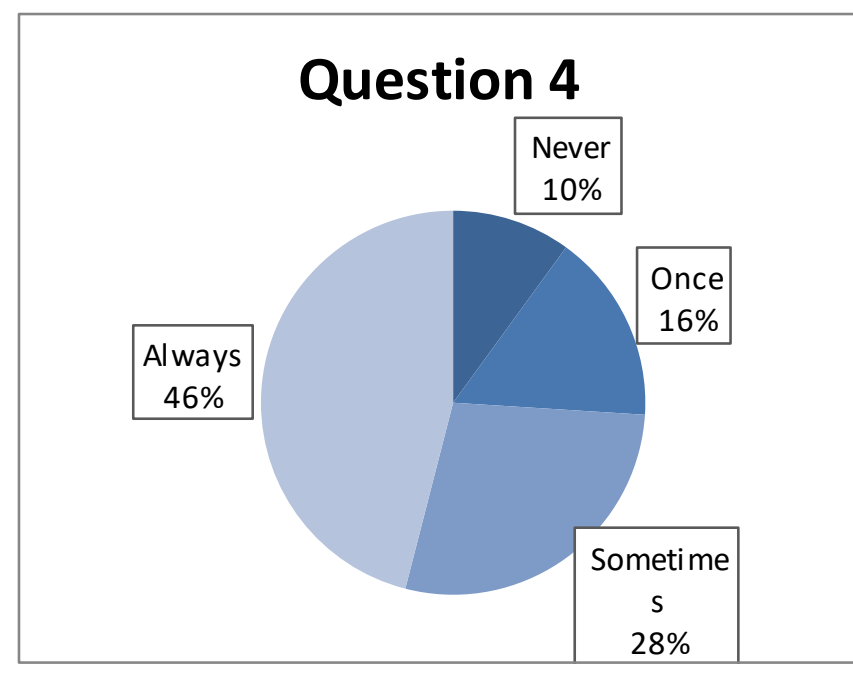

Fig.4: How often do you use language like Exclamatory spelling of emoticons. (For example hahaha, wah, wooh)

In a result of the table above, $46 \%$ of the respondents always used language like exclamatory spelling of emoticons, $28 \%$ for sometimes, $16 \%$ belongs to once and the rest which is $10 \%$ of the respondents never used the statement mentioned.

Scott (2010) in an article entitled Discourse of Twitter and Social Media, believed Emoticons are can pose a significant problem. Depending on the configuration of the concordance software used, some of the characters used in emoticons are not considered valid letters for that system, they may also be interpreted as marking word breaks. In addition some characters may have other special meanings to the system.

Through the use of social media channels like Facebook, Twitter etc. the old words are having a new meaning based on the usage of the words on the said channels. The language of the internet now becomes the language of the world wherein there's no grammar being followed.

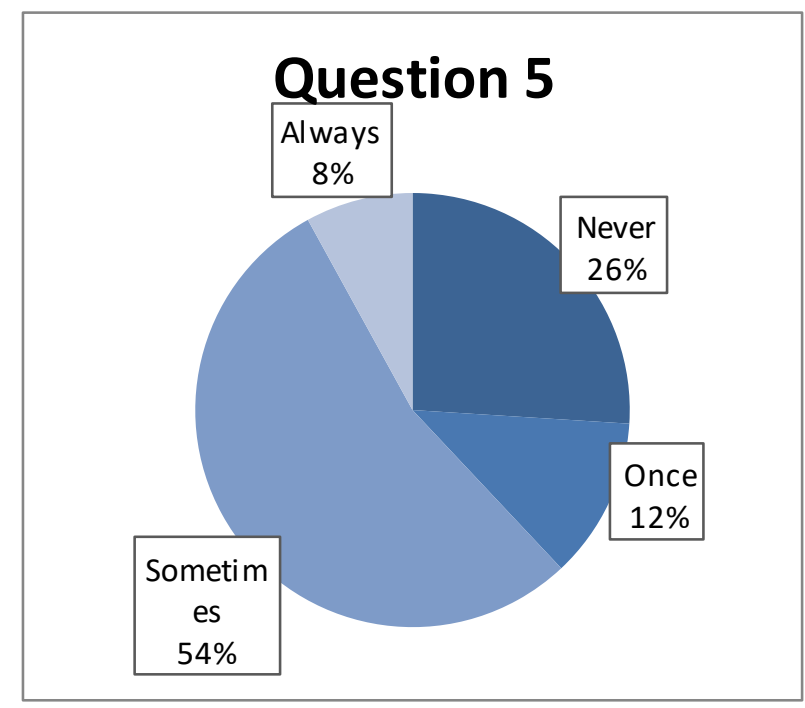

Fig.5: How often you use letter homophones (Example: U to represents the word" You"

In the given question above $26 \%$ of the SNSs users have never been used letter homophones, $8 \%$ of the respondents always used letter homophones, $54 \%$ of them sometimes used homophones and the rest which is $12 \%$ used homophones once.

According to Plester et al., (2008) in a journal entitled Txt msg $n$ school literacy: Does texting and knowledge of text abbreviations adversely affect children's literacy attainment? Literacy, stated that Internet slang and short message services have been shown to have an impact on the English language. Internet slang was invented for the purpose of saving keystrokes. As typing is much slower than speaking, in order to counter this problem, people started shortening words and creating new words. 


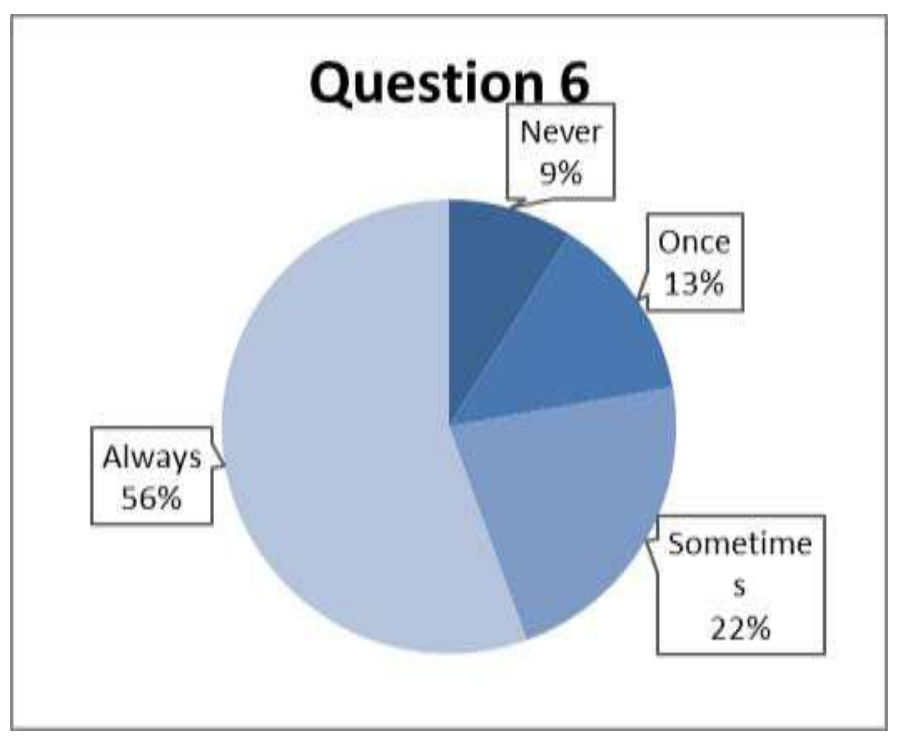

Fig.6: How often do you use Acronyms (Example: LOL, ATM, JGH, IDK, OTW, BRB)

As a result in the table 6 answered the question of how often they used Acronyms 9\% always used, 53\% used sometimes, $8 \%$ used once and the respondents whose never used Acronyms is $30 \%$.

According to Mphalele and Mashamaite (2005), in the book entitled "The impact of short message service (sms) language on language proficiency of learners and the sms dictionaries: A challenge for educators and lexicographers" stated that in order to save space, time, and money. Mobile phone users can communicate with others by using symbols or abbreviated forms of words and sentences.

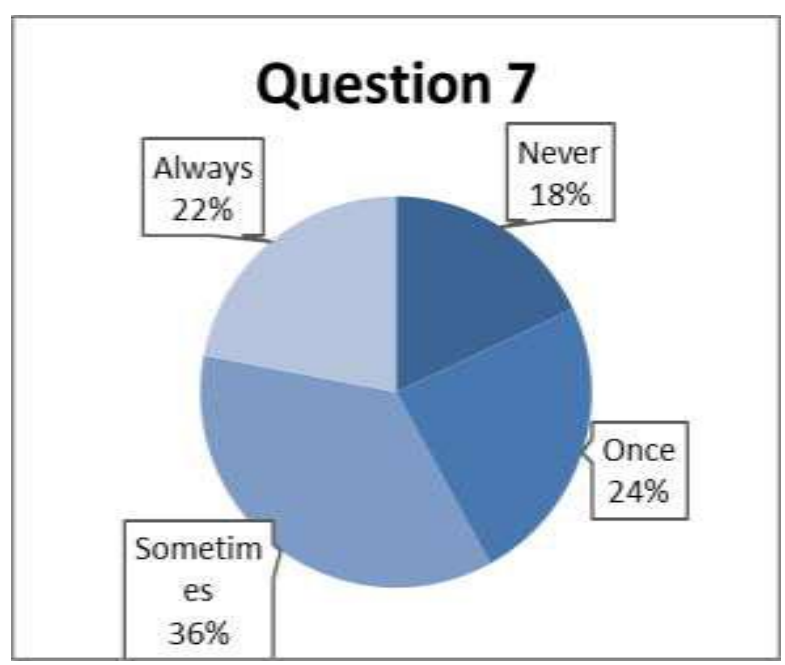

Fig.7: How often do you commit misspelled words?

In a result of question 7 the respondents admit that $15 \%$ of them always commit misspelled words, $70 \%$ commit sometimes, $10 \%$ for once and the remaining $5 \%$ never commit misspelled words.
According to Mphahlele \& Mashamaite (2005), text messaging is deemed to be detrimental to students' language proficiency since students mix this "text language" with the standard language they learn at school. Consequently, students displayed numerous errors ranging from incorrect spellings to "ungrammatical" sentence constructions.

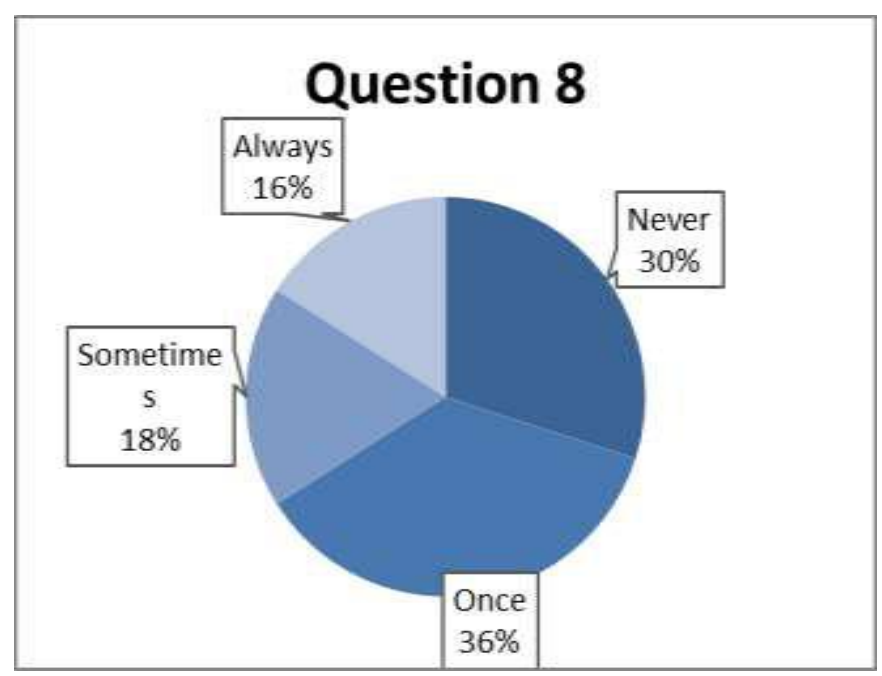

Fig.8: How often do you use shortening of words? (Examples: msg. instead of messages and tnx. Instead of thanks)

As a result in the given question above $15 \%$ of the respondents always used shortening of words, $20 \%$ of them used sometimes while $40 \%$ of them use once and the rest which is $25 \%$ never used shortening of words.

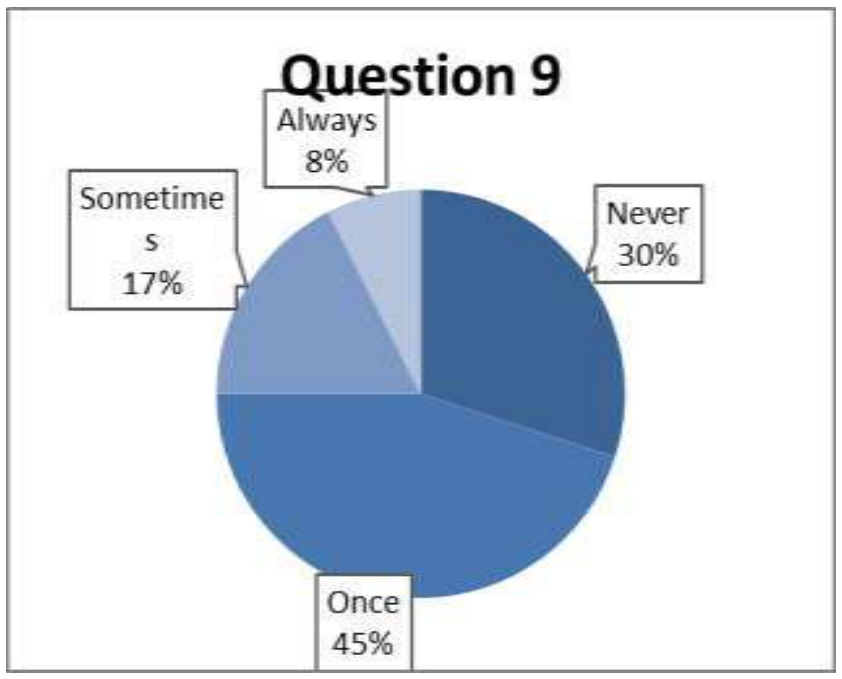

Fig.9: How often do you use numbers to represents words? (Example: 143 represents I love you.)

$10 \%$ of the respondents always used numbers to represent words, $20 \%$ of this are the respondents who used sometime, $\mathbf{1 0 \%}$ for used once and the remaining $60 \%$ are 
those respondents who never used numbers to represents words.

According to Plester et al., (2008) in a journal entitled Txt msg n school literacy: Does texting and knowledge of text abbreviations adversely affect children's literacy attainment? Literacy, stated that Internet slang and short message services have been shown to have an impact on the English language. It was estimated that $90 \%$ of school children owned a mobile phone, and $96 \%$ used text messaging. This shows that young people are active "texters". Internet slang was invented for the purpose of saving keystrokes. As typing is much slower than speaking, in order to counter this problem, people started shortening words and creating new words.

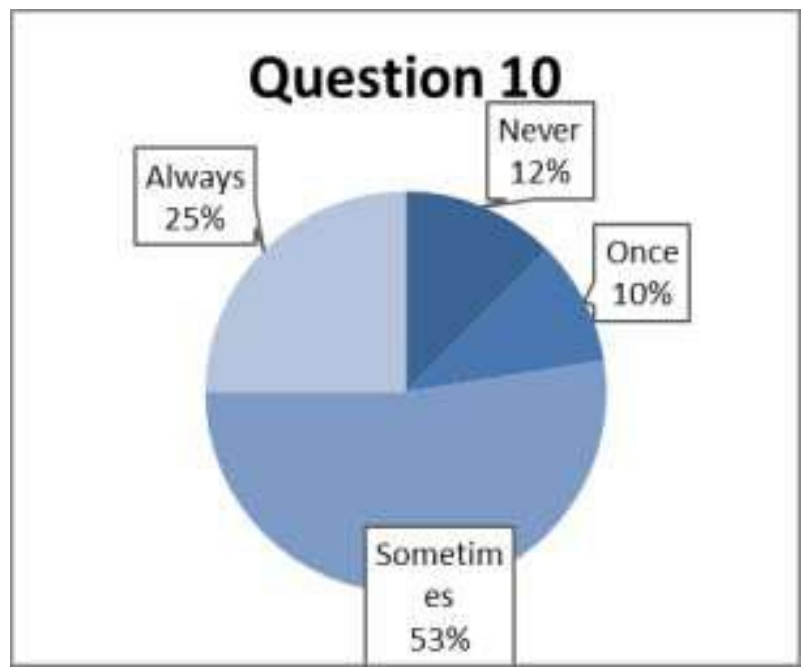

Fig.10: How often do you use combination of two different language? (Example: Taglish)

In question number $10,33 \%$ of the respondents always used combination of two different language like Taglish, $52 \%$ of them sometimes used, while $5 \%$ of them used once and lastly the remaining $10 \%$ never used combination of different language.

Abdul Kadir \& Zubir (2012) on e-distance learning students in a public university in Malaysia. The study found that code-switching occurs intentionally and not through lack of competence in the base language. The students used code-switching functions for various purposes such as to capture attention, to show respect, to show empathy and to indicate a shift in topic

General Question 1: How does Social Media affects the formal English Language by using the following given questions above?

Based on the answered of the respondents most of them stated that Social Media affects the formal English Language by using different language usage or the given questions above. First, of course the formality of language will vanish and according to them it is one of the problem of the "millennial" because nowadays our country is modernized by the use of modern technology and the Social Media. They create their own language and influence one another by using those kind of form of language.

According to John Simpson (2014), Facebook has also done more than most platforms to offer up new meanings for common words such as friend, like, status, wall, page, and profile. Other new meanings which crop up on social media channels also reflect the dark side of social media: a troll is no longer just a character from Norse folklore, but someone who makes offensive or provocative comments online; a sock puppet is no longer solely a puppet made from an old sock, but a self-serving fake online persona; and astrosurfing is no longer simply laying a plastic lawn but also a fake online grass-roots movement.

\section{General Question 2}

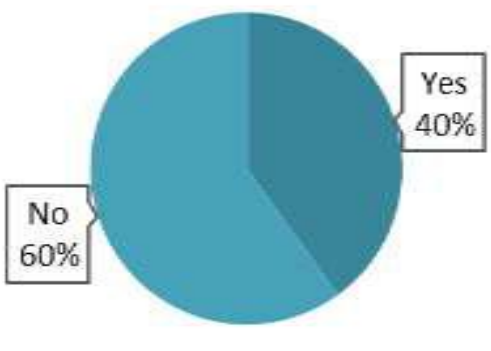

Fig. 11: Are you in favor of using different language usage in Social Media with regards in the formal English Language in the academe?

In general question number 2, 40\% of the respondents answered yes in favor of using different language usage in social media with regards in the formal English language in the academe, on the other hand $60 \%$ of the respondent disagree or answered no in the given question stated above.

Drouin (2011) examined the frequency of text messaging, use of "textese" and literacy skills (e.g., reading accuracy, spelling and reading fluency) in a sample of college students in America. Co-relational analyses revealed significant positive relationships between text messaging frequency and literacy skills (spelling and reading fluency) but significant, negative relationships between textese usage in certain contexts (e.g. emails to professors) and literacy (reading accuracy). Those reportedly using more textese on SNSs and those 
using more textese in emails to professors had significantly lower reading accuracy scores.

\section{CONCLUSION AND RECOMMENDATION}

Conclusion

The result shows that most of the respondents are 18 years old and most of them are female. $90 \%$ of the respondents always use Social Networking Sites that they preferred such as Facebook and Twitter. In communicating with their friends via SNSs and mobile phone, $62 \%$ of them sometimes uses only one language. On the other hand, $84 \%$ of the respondents sometimes use proper abbreviations or short forms when communicating with friends through SNSs. Most of the respondents always use language like exclamatory spelling of emoticons for example Haha! Huhu! and Wooh! With the rate of $65 \%$. While $60 \%$ of the SNSs users have never been used letter homophones like $\mathrm{U}$ for the word YOU and D for the word THE. According to the results $53 \%$ of the respondents use acronyms like LOL, ATM, JGH, IDK, FYI, and OTW. Most of the respondents commits misspelled words in their daily communication with friends. Out of 20 respondents, $40 \%$ of them once used shortening of words such as msg. instead of message, and thx instead of the word thanks. Moreover, $60 \%$ of the respondents never used number to represent words for example 143 to represent I Love You. Most of the respondents sometimes uses the combination of two different language like Filipino and English in communicating through Social Media. Therefore Social Networking Sites like Facebook creates their own language and adapts and influence one another by using different language usage such as using Acronyms, Shortening of words, Letter homophones and Exclamatory spelling of Emoticons. They also disagree that the newly created words by the language usage they are using in Social Media in the Formal English Language used in the Academe.

Recommendation

Based on the findings and conclusions presented, the researchers' offers suggestions and the recommendations are suggested:

1. The researcher recommend to the future researchers to maximize the respondents in gathering of their data. They should become fair for choosing respondents either male or female to know their opinions in certain issues.

2. The researcher suggest to the future researchers to use Survey Questionnaire because it is one of the effective style in gathering of data in which you can use Convenience Sampling to minimize the time and you can efficiently proceed to the next chapter of you research.

3. The researcher offer to the future researchers to use topic about modernization in $21^{\text {st }}$ century that can actually more understand by the respondents. It can be the development of language by generation to generation and how people deal with that kind of language.

Those statement mentioned above is an alternative formal recommendation for the future researcher that is best supported in conducting their study.

\section{REFERENCES}

[1] Abdul Kadir, Z. \& Zubir, Z. (2012). Code-switching in Edistance learning education. Paper presented at the International Conference on Humanity, History \& Society. IPEDR. Vol 34. Singapore: IACSIT Press.

[2] Aydin, S. (2012). A review of research on Facebook as an educational environment. Education Tech Research Development.

[3] Craig, D. (2003). Instant messaging: The language of youth literacy. The Boothe Prize Essays 2003, 118-119.

[4] Cummings, A.B. (2011). An experience with language. ProQuest Dissertations \& Theses: Literature \& Language, 10.

[5] Drouin, M.A. (2011). College students' text messaging, use of textese and literacy skills. Journal of Computer Assisted Learning, 27, 67-75.

[6] Kaplan, A. Haenlein, M. (2010). Users of the World, Unite! The Challenges and Opportunities of Social Media. Muthusamy, P. (2009). Communicative functions and reasons for code switching: A Malaysian perspective.

[7] Retrieved on 5 August, 2011 from www.crisaps.org/newsletter/summer2009/Muthusamy.doc. Plester, B., Wood, C. \& Bell, V. (2008). Txt msg n school literacy: Does texting and knowledge of text abbreviations adversely affect children's literacy attainment? Literacy. 42(3), 137-144.

[8] Mphahlele M.L. \& Mashamaite, K. (2005). The impact of short message service (sms) language on language proficiency of learners and the sms dictionaries: A challenge for educators and lexicographers. Proceedings of the IADIS International Conference Mobile Learning 2005, 161.

[9] Plester, B., Wood, C. \& Bell, V. (2008). Txt msg n school literacy: Does texting and knowledge of text abbreviations adversely affect children's literacy attainment? Literacy. 42(3), 137-144.

[10] Schonfeld, Zappavigna, M. (2010). Discourse of Twitter and Social Media: How We Use Language to Create Affiliation of the Web. 10, A\&C Black, 2012.

[11] Scott, Zappavigna, M. (2010). Discourse of Twitter and Social Media: How We Use Language to Create Affiliation of the Web. 10, A\&C Black, 2012. 
[12] Simpson, J. (2014). Oxford Dictionary. Oxford University Press. Retrieved from http://blog.oxforddictionaries.com/2014/06/social-mediachanging-language/

[13] Thurairaj, S. and Roy,S.S., 2012. Teachers' Emotions in ELT Material Design. International Journal of Social Science and Humanity, 2(3), 232-236. www.ejel.

[14] Thurairaj, S. and Roy,S.S., (2012). Reflections of Students' language Usage in Social Networking Sites: Making or Marring Academic English (15) www.ejel.

[15] Wadsworth, T. (2017). Impact of Social Media on English Language. Retrieved from https://www.slideshare.net/mobile/social-media-violatedenglish-language

[16] https://www.teachingenglish.org.UK/article/ languageusage

[17] PDF (The Impact of Social Media on Vocabulary learning Case Study) 